\title{
Reversal of visual discrimination problem and differential frustration effects in dominant and submissive rats
}

\author{
D. J. COSTANZO, P. G. HENKE*, and D. R. BOSLEY $\dagger$ \\ Muskingum College, New Concord, Ohio 43762
}

\begin{abstract}
Two experiments are reported comparing performance in dominant and submissive rats as determined by a food-competition procedure. Ss in Experiment I were either trained to criterion or overtrained before being reversed on a visual discrimination task. Although the two groups did not differ significantly in learning the initial task, the dominant Ss were significantly slower on reversal than the submissives. Experiment II, which utilized a tandem runway, showed that when the reinforcer which maintained the running response was not available in the first goalbox, submissive rats responded with a greater increase in running speed in the second runway than dominant rats. These findings were discussed as reflecting motivational differences between dominant and submissive rats.
\end{abstract}

There is considerable evidence that there are factors related to an organism's social rank which influence how it will perform in learning situations. Compared to subordinates, dominant rabbits (Brown, 1937) and pigeons (Collins \& Cavanaugh, 1970) have been shown to respond more vigorously in conditioning experiments, while dominant monkeys (Levine \& Gordon, 1968) and mice (Hudgens \& MacNeil, 1970) have been shown to be poorer in avoidance learning. It has also been shown that dominant monkeys have lower rates of operant responding than submissives (Bartlett \& Meier, 1971). And dominant crayfish have been shown to have habit-reversal learning deficits in comparison with lower-ranked conspecifics (Costanzo, Rudolph, \& Cox, 1972). The bases for these various relationships are not clear, and no data of this kind are available for the laboratory rat.

\section{EXPERIMENT I}

This experiment was performed to determine whether the factor of dominance and submissiveness in rats affects performance in a visual, discrimination reversal task. A habit-reversal procedure was employed, since many of the factors affecting it have been defined. Such a procedure permits the observation not only of simple acquisition but also of reversal, where status-related factors may be of greater importance. A variation of such a procedure with socially ranked crayfish revealed differences only during reversal learning (Costanzo et al, 1972).

\section{Method}

Subjects

Forty-eight experimentally naive male Wistar rats were *Now at St, Francis Xavier University, Antigonish, Nova
Scotia.

+Now at The Ohio State University, Columbus, Ohio. randomly paired at the age of 50 days. Each pair was housed in a single Wahmann rodent cage, and a 12 -h day-night cycle was provided.

\section{Apparatus and Procedure}

Dominance Testing. One month after Ss were paired, they were fed powdered lab chow in Wahmann LC-306 feeding cups mounted in each cage's front wall. The cups permitted only one animal to feed at any time. Following 1 week of experience with the feeding cups, all pairs were placed on 23-h food deprivation. This maintenance schedule was in effect for the next week, and sbusequently the pairs were tested during food competition for 5 consecutive days. Each pair was tested during the initial $10 \mathrm{~min}$ of food competition. For the duration of these test periods, the water bottles were removed from the cages. The amount of time each $S$ controlled the feeding cup (extended its nose into the cup) was measured, and an $\mathrm{S}$ was classified as dominant (and its cagemate submissive) if it controlled the feeding cup at least during the last four of the testing sessions without constantly pushing its partner aside for this access. Fifteen pairs met this criterion and were selected as Ss.

When both members of a pair had completed the reversal problem, they were again paired and retested twice to determine the stability of the relationship.

Training. Once dominance was established, Ss were separated into single housing units, allowed $2 \mathrm{~h}$ of free access to food (no competition), and then deprived for $22 \mathrm{~h}$. This deprivation schedule was maintained throughout the remainder of the experiment.

The Ss were trained in a Lafayette Model 85304 Y-maze, equipped with a manually operated guillotine door between startbox and maze and top-hinged doors to the goalboxes which were slotted to accept stimulus cards. First, each $\mathrm{S}$ was given $20 \mathrm{~min}$ of habituation to the Y-maze while all the doors were open and then was fed in its home cage. During the next 3 days, each $\mathrm{S}$ was given a total of 14 reinforced pretraining trials, (10 45-mg Noyes pellets per trial) 7 of which were forced to be experienced in either arm of the maze.

Following pretraining, white and gray stimulus cards were mounted on the goalbox doors. The cards were positioned according to Gellerman series and, for half of the Ss, white was the positive stimulus; for the others, responses to gray were reinforced (10 pellets). All Ss were given 10 noncorrection trials per day with intertrial intervals of 2-5 min. After correct responses, they were allowed to consume the reward; following 
incorrect choices, they were detained for $10 \mathrm{sec}$ in the goalbox. The criterion for discrimination learning was 9 correct in any 10 consecutive trials. Three submissive and two dominant Ss were eliminated for failing to learn the initial discrimination (within 200 trials) or developing a position habit during overtraining (8 out of 10 days). Seven dominant and five submissive Ss were reversed immediately after reaching criterion; the remaining Ss received 100 overtraining trials before being reversed. Those Ss that failed to reach criterion within 200 trials during reversal learning were retained and given a score of 200 .

\section{Results}

The relationships were found to be stable, since only one of the pairs failed to maintain their original rankings for both of the dominance retests.

As shown in Table 1, there were no significant differences between groups in the number of trials or errors to criterion in learning the initial discrimination, or in the number of errors made during overtraining. Table 2 summarizes reversal learning in terms of average number of trials and errors to criterion for both the criterion-trained and overtrained Ss. Unweighted means ANOVAs (Winer, 1962) applied to both errors to criterion $(\mathrm{F}=4.72, \mathrm{df}=1 / 20, \mathrm{p}<.05)$ and trials to criterion $(F=5.48, d f=1 / 20, p<.05)$ indicated a significantly poorer performance by the dominant $S$ s in learning the reversal. There was no significant main effect for the amount of training with either measure, nor was there a significant interaction $(p>.1)$.

\section{EXPERIMENT II}

Since in the first experiment there were no significant differences during acquisition or overtraining between dominants and submissives, it is questionable that learning factors were responsible for the performance deficits of the dominant rats during reversal training. It is possible that a difference in frustration in discrimination reversal learning (Amsel \& Ward, 1965) is a factor in the difference between dominant and submissive rats. The purpose of the second experiment was to investigate whether or not the poorer performance of the dominant $S s$ is related to differences in response to absence of reward (frustration).

\section{Method}

\section{Subjects}

Twenty-six experimentally naive male Wistar rats were randomly paired at the age of 40 days and maintained as in Experiment I. Two months after Ss were paired, the feeding cups were introduced in the home cages, and each dominant-submissive relationship was determined by the procedure reported in the first experiment except that the cup was removed after each $10-\mathrm{min}$ test and free access to standard lab chow was provided for the last $50 \mathrm{~min}$. Ten pairs developed stable relationships, were selected for the study, and were separated into individual cages. After completion of the study (44 days later), they were paired again and retested for dominance rank for 3 days.
Table 1

Average Number of Trials and Errors to Criterion During Acquisition and Average Number of Errors Made During Overtraining

\begin{tabular}{lccccc}
\hline Measure & Dominant & $\mathrm{N}$ & Submissive & $\mathrm{N}$ & $\mathrm{t}$ \\
\hline Acquisition & & 13 & & 11 & \\
$\quad$ Errors & 32.2 & & 24.4 & & $1.31^{*}$ \\
$\quad \begin{array}{l}\text { Trials } \\
\text { Overtraining }\end{array}$ & 84.8 & 6 & 52.7 & \multirow{6}{*}{6} & $1.46^{*}$ \\
$\quad$ Errors & 22.3 & & 20.2 & & $.52^{*}$ \\
\hline
\end{tabular}

${ }^{*} p>. I$ (two-tailed test)

Table 2

Average Number of Trials and Errors to Criterion During Reversal Training

\begin{tabular}{llrr}
\hline Group & N & Errors & Trials \\
\hline Dominant & & & \\
$\quad$ Criterion Trained & 7 & 39.3 & 78.7 \\
$\quad$ Overtrained & 6 & 28.3 & 63.0 \\
Submissive & & & \\
$\quad$ Criterion Trained & 5 & 10.0 & 21.2 \\
$\quad$ Overtrained & 6 & 7.2 & 15.3 \\
\hline
\end{tabular}

\section{Apparatus}

The apparatus consisted of two runways in series (Amsel \& Roussel, 1952) which formed a straight runway, $320 \mathrm{~cm}$ long. It was divided into five sections: a starting box, followed by an alley (A1), a goalbox (G1), a second alley (A2), and another goalbox (G2). Lafayette Model 85000 modular testing units, equipped with pivoted sensors, served as startbox and goalboxes. Each wooden alley was $114.3 \times 11.4 \times 127 \mathrm{~cm}$ and covered with a hinged lid of clear Plexiglas. A1 and a circular metal food cup in $\mathrm{G} 1,6.6 \mathrm{~cm}$ in diam and $1.5 \mathrm{~cm}$ deep, were painted black, A2 and a similar foodcup in G2 were painted white. Manually operated guillotine doors separated the five sections of the runway. Electric stopclocks automatically measured running times over each $114.3-\mathrm{cm}$ alley to the nearest 01 . sec.

\section{Procedure}

Pretraining. Ss were separated into single cages and the same deprivation schedule was maintained. Seven days after $S$ s had been separated, 12 pretraining trials ( 4 trials per day) were given in the double runway. The foodcups in $G 1$ and $G 2$ contained three 45-mg Noyes pellets on each trial. All doors were opened in the apparatus and, if $S$ did not leave any section of the runway within $5 \mathrm{~min}$, it was moved to the next section.

Training. $S$ was placed in the startbox, and after $10 \mathrm{sec}$ the sliding door to $A 1$ was raised. After running $A 1, S$ was allowed to consume the Noyes pellets in G1. After $15 \mathrm{sec}$ in $\mathrm{G} 1$, the door to A2 was opened and $S$ was allowed $15 \sec$ to consume the same amount of reinforcement in G2. After each trial, $S$ was returned to its home cage. Each $S$ received four trials per day in rotation with the intertrial intervals ranging from $8-12 \mathrm{~min}$. After 12 days of training (48 trials), frustration trials were introduced.

Frustration Testing. The animals were run exactly as during training (four trials per day) except that on $50 \%$ of the trials, reinforcement was omitted in G1. The sequence of reinforced (R) and nonreinforced (F) trials was irregular but with the restriction that an equal number of $R$ and $F$ trials occurred during each 2-day period. Increases in G2 running speed following $F$ trials constituted a frustration effect (FE). 


\section{Results}

All of the pairs were dominance tested again and were found to be stable. None of the pairs showed a change in rank during any of the three retests.

Figure 1 shows the running speeds (1 per running time) of dominant and submissive animals in A2. An analysis of variance of $\mathrm{A} 2$ performance during training indicated that running speeds increased significantly over blocks of trials $(\mathrm{F}=10.59, \mathrm{df}=11 / 198, \mathrm{p}<.01)$, but there was no significant difference between groups $(\mathrm{F}=2.30, \mathrm{df}=1 / 18, \mathrm{p}<.10)$. Similar results were found for A1 running speeds, showing an increase over blocks of trials $(F=6.48, \mathrm{df}=11 / 198, \mathrm{p}<.01)$ but no significant differences between groups $(F=1.02$, $\mathrm{df}=1 / 18, p<.10)$. It is apparent that both groups reached similar asymptotes before frustration trials were introduced.

An analysis of variance of running speeds during the test blocks (Fig. 1) indicated a significant $F E(F=43.60$, $\mathrm{df}=1 / 18, \quad \mathrm{p}<.01)$, a significant Groups by $\mathrm{FE}$ interaction $(F=25.93, \mathrm{df}=1 / 18, \mathrm{p}<.01)$, a significant Groups by Blocks interaction $(\mathrm{F}=10.83, \mathrm{df}=3 / 54$, $\mathrm{p}<.01$ ), and a significant $\mathrm{FE}$ by Blocks interaction $(\mathrm{F}=4.40, \mathrm{df}=3 / 54, \mathrm{p}<.01)$. The Newman-Keuls test showed a significant FE only on the first block of trials by dominant Ss whereas the submissive group responded at increased speeds during all $F$ blocks of trials $(p<.01)$.

\section{Discussion}

A relationship between performance in a learning situation and the social status of rats was demonstrated. Although results of Experiment I indicated no significant difference between dominant and submissive Ss during acquisition or overtraining, dominant rats were poorer than submissives at learning the reversal problem. Similar effects have been shown with socially ranked crayfish learning a combined visual-spatial reversal problem (Costanzo et al, 1972). In view of these results and the reported poorer learning performance of dominant monkeys (Bartlett \& Meier, 1971; Levine \& Gordon, 1968) and dominant mice (Hudgens \& MacNeil, 1970), it appears that, in general, there is an inverse relationship between dominance and performance in certain learning situations.

Experiment II demonstrated the presence of a differential response to nonreinforcement in dominant vs submissive rats, supporting the hypothesis that motivational, not learning, factors underlie the obtained difference in reversal performance. A status-related motivational factor could serve as an explanation for the reported differences between socially ranked pigeons (Collins \& Cavanaugh, 1970) and rabbits (Brown, 1937). The performance of both species was partly reported in terms of differences in vigor and magnitude of responding, which are indexes of motivational levels.

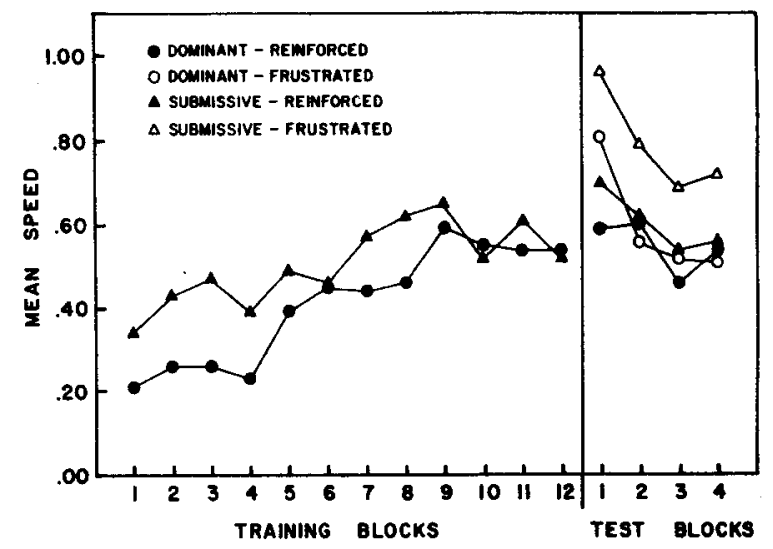

Fig. 1. Alley 2 mean running speeds (1 per running time) in blocks of four trials for dominant and submissive rats during training and $R$ vs $F$ (reinforced vs nonreinforced) test trials.

The demonstration of a greater FE by the submissive Ss allows a more specific interpretation of the poorer reversal performance of the dominant $S s$ in Experiment I. According to one theory (Amsel, 1958), primary frustration $\left(R_{F}\right)$ is a motivational condition which results when a previously rewarded response is not rewarded. It is assumed that $R_{F}$ gives rise to the conditioning of a fractional anticipatory component $\left(\mathrm{r}_{\mathrm{F}}-\mathrm{s}_{\mathrm{F}}\right)$ which represents the inhibitory mechanism following nonreinforcement. The present results suggest that submissive animals develop a greater magnitude of primary frustration in response to nonreward in the double alley. If it can be assumed that $R_{F}$ is greater in submissive animals following nonreward in other learning situations, then, for example, decreased resistance to extinction reported in submissive pigeons (Collins \& Cavanaugh, 1970) and better reversal performance by the submissive rats in Experiment $I$ could be the result of faster development of the $r_{F}-s_{F}$ mechanism.

A less specific interpretation is possible if it is assumed that there is an inverse relationship between status and emotionality. The Ss in this study were not tested for emotionality, but other Es have demonstrated such a relationship. When paired with more emotional conspecifics, less emotional rats have been shown to dominate and be more aggressive toward their partners (Becker \& Gaudet, 1968; Hall \& Klein, 1942). The dominant $S s$ in the present study may, likewise, have differed from submissives along this dimension. If this were the case, they would show smaller emotional reactions to habit reversal and nonreward.

Regardless of the interpretation, it is clear that the dominance-submissiveness relationship between rats affects performance in nonsocial situations and that such effects have also been noted in other organisms.

\section{REFERENCES}

Amsel, A. The role of frustrative nonreward in noncontinuous 
reward situations. Psychological Bulletin, 1958, 55, 102-119.

Amsel, A.. \& Roussel, J. Motivational properties of frustration: I. Effect on a running response of the addition of frustration to the motivational complex. Journal of Experimental Psychology, 1952, 43, 363-368.

Amsel, A. \& Ward, J. S. Frustration and persistence: Resistance to discrimination following prior experience with the discriminanda. Psychological Monographs, 1965, 79(4, Whole No. 597).

Bartlett, D. P., \& Meier, G. W. Dominance status and certain operants in a communal colony of rhesus macaques. Primates, 1971, 12, 209-219.

Becker, G., \& Gaudet, I. J. Defecation and ambulation in a novel environment as determinants of dominance-subordination polarity in the rat. Psychonomic Science, 1968, 12, 7-8.

Brown, R. H. Stability of conditioning and sexual dominance. Science, $1937,86,520$.

Collins, T. B., \& Cavanaugh, F. B. R esponding during extinction by dominant and submissive pigeons. Paper presented at
Midwestern Psychological Association, Cincinnati, 1970.

Costanzo, D. J., Rudolph, G. R., \& Cox, W. Social status and learning in crayfish. Journal of Biological Psychology, 1972 , $14,30-32$.

Hall, C. S., \& Klein, S. J. Individual differences in aggressiveness in rats. Journal of Comparative Psychology, 1942, 33, 371-383.

Hudgens, G. A., \& MacNeil, D. A. Aggressiveness and learning ability: Effect of histories of wins or defeats on avoidance learning in mice. Psychonomic Science, 1970, 20, 51-53.

Levine, M. D., \& Gordon, T. P. Emotional response of rhesus monkeys to chronic psychological stress. Proceedings of the Army Science Conference, 1968, 2, 17-25.

Winer, B. J. Statistical principles in experimental design. New York: McGraw-Hill, 1969, P. 241.

(Received for publication November 10, 1973; 2nd revision received July 8,1974 .) 